The Regulation of Heme Synthesis: Studies on Erythrocyte Aminolevulinic Acid Synthetase

\title{
Pr. Mckinick
}

\author{
John D. Vavra
}

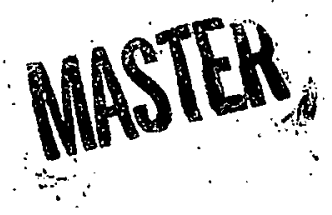

(Slide 1) The synthesis of aminolevulinic acid (ALA) is the first in a series of enzymatic reactions leading to the formation of tetrapyrrols and heme. The reactions show on this slide as well as the final two steps in heme synthesis are localized within mitochondria. This fact has implicated the synthesis of ALA as the site of a feedback control mechanism whereby heme synthesis may be regulated and integrated with the formation of other parts of the hemoglobin molecule. The following studies were performed: (1) to characterize the kinetics of the synthesis of ALA for enzyme obtained from chicken erythrocytes and (2) to identify and ascertain the importance of potential physiological inhibitors in controlling the rate of herne synthesis.

A crude preparation of mitochondria capable of carrying out the reactions shown on this slide was obtained from reticulocytes of anemic chickens. The preparation was free of hemoglobin and enzymes utilizing ALA so that its formation could be followed. Incubations for one hour were performed at pH optimal for ALA synthetase varying the concentration of substrate to permit construction of standard doublereciprocal Lineweaver-Burke plots. In the present studies Succinyl CoA was generated either from dketoglutarate or from succinate in the presence of optimal concentrations of cofactors for the reactions, as noted on the slide, and relying upon $\alpha$ KG oxidase and succinyl CoA synthetase known to be present in mitochondria of the preparation.

(Slide 2) The right-hand portion of this slide demonstrates the standard double-reciprocal plots with Qketoglutarate concentration on the abscissa and ALA formed, expressed as lunoles per milliliter per hour, on the ordinate for four concen- 


\section{DISCLAIMER}

This report was prepared as an account of work sponsored by an agency of the United States Government. Neither the United States Government nor any agency Thereof, nor any of their employees, makes any warranty, express or implied, or assumes any legal liability or responsibility for the accuracy, completeness, or usefulness of any information, apparatus, product, or process disclosed, or represents that its use would not infringe privately owned rights. Reference herein to any specific commercial product, process, or service by trade name, trademark, manufacturer, or otherwise does not necessarily constitute or imply its endorsement, recommendation, or favoring by the United States Government or any agency thereof. The views and opinions of authors expressed herein do not necessarily state or reflect those of the United States Government or any agency thereof. 


\section{DISCLAIMER}

Portions of this document may be illegible in electronic image products. Images are produced from the best available original document. 
trations of glycine represented by each of the lines. A secondary plot of the reciprocals of the maximal velocities for each of the lines, as obtained where the lines cross the ordinate, and the reciprocal of the respective glycine concentration, gives a Michaelis constant for glycine of $13 \mathrm{mM}$. This constant represents the concentration of glycine yielding half-maximal velocity for ALA formation. (Slide 3) When these same data are plotted first for the reciprocal of the glycine concentration on the abscissa and reciprocal of ALA formed on the ordinate, a similar family of curves is obtained, each line now representing a different concentration of $\alpha K G$. A secondary plot of the reciprocal of the maximal velocity for each line against the reciprocal of the $\alpha K G$ concentration yields a Michaelis constant for $\alpha$ KG of $0.21 \mathrm{mM}$.

(Slide 4) When the formation of ALA is followed utilizing glycine and succinate as substrates, another family of curves is obtained. These curves, which I shall not show, are similar to the ones show on the previous two slides except that succinate would replace $\alpha K G$. In these reactions the Michaelis constant for glycine is the same for both $\alpha \mathrm{KG}$ and succinate as substrates. However, the Michaelis constant. for succinate, obtained from a secondary plot, is $1.7 \mathrm{mM}$ compared to the $0.21 \mathrm{mM}$ for «KG. The eightfold higher Michaelis constant for succinate compared with $\alpha$ KG indicates that succinyl $\mathrm{COA}$ is generated more effectively from $\alpha \mathrm{KG}$ than from succinate. This difference can be accounted for in part by the equilibrium between succinyl COA and succinate which favors the breakdown of succinyl CoA by a factor of 4 times its synthesis.

The reactions synthesizing ALA from glycine and dketoglutarate or succinate are described by Michaelis-Menton kinetics for a two substrate reaction with sequential addition of substrates but without specifying their order of addition. The synthesis of ALA is dependent upon the presence of divalent ions, either magnesium (Mg++) or 
iron $(\mathrm{Fe}++)$. It is of interest that increasing iron concentrations above $0.01 \mathrm{mg} / \mathrm{ml}$ are attended by a progressive decrease in ALA synthesized.

(Slide 5) The next series of slides are representative of some experiments designed to evaluate the effectiveness of hemoglobin or parts of the hemoglobin molecule in inhibiting or influencing the enzymatic synthesis of ALA. The slides are constructed showing two panels. The standard double-reciprocal plot is shown above, with the reciprocal of ALA formed on the ordinate, the reciprocal of $\alpha K G$ as substrate on the abscissa, and a fixed optimal concentration of glycine. Each line now represents a different concentration of inhibitor, in this case hemoglobin. The progressive shift of the lines upward with increasing hemoglobin concentration and their intersection to the left of the ordinate is indicative of mixed competitive inhibition by hemoglobin. Show on the lower panel is an inhibitor plot on which the same points are plotted, but in this case the reciprocal of ALA formed against the concentration of inhibitor at different concentrations of $\alpha K G$. The intersection of these lines gives an inhibitor constant which represents the concentration of inhibitor at which the reaction is half inhibited. This slide indicates that at a concentration. of human hemoglobin of about $8 \mathrm{Gm} / 100 \mathrm{ml}$, ALA formation is inhibited by 50 per cent. When succinate was used instead of $\alpha K G$, a similar group of curves were obtained and a similar Inhibitor constant. Chicken hemoglobin as inhibitor gave a comparable group of curves for both $\alpha K G$ and succinate, however the inhibitor constant was $1.0 \mathrm{Gm} /$ $100 \mathrm{ml}$ indicating it is a six to eightfold better inhibitor than human hemoglobin.

The inhibition by hemoglobin is independent of the oxidation state of iron. in heme. Human methemoglobin, with iron in the ferric valence state, gave a similar group of curves as the ones shown here and an inhibitor constant of 8 to $10 \mathrm{Gm} / 100 \mathrm{ml}$. (Slide 6) Human globin prepared by removing the heme group gave similar pattern 
of inhibition and inhibitor constant as hemoglobin, which indicates that the globin moiety is primarily responsible for inhibition. Bovine serum albumin in concentrations similar to those shown here for globin produced no inhibition of ALA synthesis indicating that the inhibition observed for globin is not due to non-specific protein inhibition. The next slide ( (Slide 7)) demonstrates that B-globin chains prepared from human hemoglobin also inhibit enzyme activity with an inhibitor constant of $0.9 \mathrm{mg} / \mathrm{ml}$, about a hundredfold smaller concentration than for hemoglobin. Human $\alpha$-globin chains also inhibited enzymatic activity in a manner identical to the plots show here with an inhibitor constant of $0.7 \mathrm{mg} / \mathrm{ml}$.

In the data I have just presented the pattern of inhibition and inhibitor constants were similar for both $\alpha_{K G}$ and succinate as. substrates, indicating that inhibition is probably on AIA synthetase. Inhibition by heme is somewhat different. (Slide 8) This slide'demonstrates the effect of heme on ALA synthesis from $\alpha K G$ in the panel above and from succinate in the panel below. At low concentrations of heme, synthesis of ALA from $\alpha K G$ was not inhibited and was perhaps even accelerated, whereas all concentrations were inhibitory for synthesis from succinate. The inhibitor to fiverold

constant for heme was fourfold, greater with $\alpha K G$ as substrate than with succinate.

(Slide 9) In summary the present studies have described the kinetics, iron dependency, and inhibition of ALA synthesis in chicken erythrocyte mitochondria. A summary of the various constants are recorded here. Inhibition by hemoglobin, globin, and polypeptide chains appears to be upon ALA synthetase with isolated chains 100 fold more effective inhibitors than the intact globin or hemoglobin molecule.

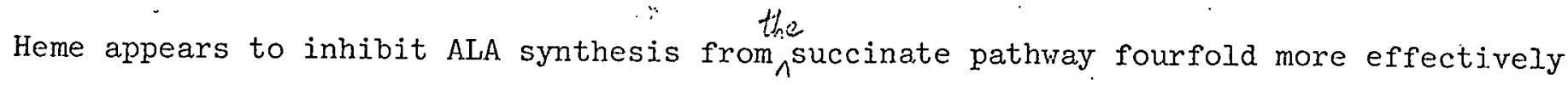
than from the $\alpha K G$ pathway. From the magnitude of the inhibitor constants alone, expressed in micromolar concentration units, it would appear that isolated globin 
peptide chains are the most effective inhibitors, particularly if succinyl CoA is generated more effectively in the reticulocyte from $\alpha$ KG rather than from succinate. Since the incubations were performed with inhibitors bathing the mitochondria in a manner similar to that occurring in the intact erythrocyte, it would appear that the hemoglobin molecule and its parts are capable of regulating the rate of ALA to synthesis, and thereby of heme synthesis. Final interpretation of these data will depend upon the demonstration that globin chains and the hemoglobin molecules are accessible to these series of enzymatic reactions synthesizing ALA in the intact reticulocyte.

\section{LEGAL NOTICE}

This report was prepared as an account of Government sponsored work. Neither the United A. Makes any warranty or represerson acting on behalf of the Commission:

A. Makes any warranty or representation, expressed or implied, with respect to the accuracy, completeness, or usefulness of the information contained in this report, or that the use priva privately owned rights; or

B. Assumes any llabllities with respect to the use of, or for damages resultung from the
use of any information, apparatus, method, As used in the above, "person acting or process disclosed in this report.

As used in the above, "person acting on behalf of the Commission" includes, any employee or contractor of the Commisaion, or employee of such contractor, to the extent such employee or contractor of the Commisaion, or employee of such contractor prent that disseminates, or provides access to, any information pursuant to his employment or contract with the Commission, or his employment with such contractor. 